1 Universidade Federal do $A B C(U F A B C)$ - São Bernardo do Campo (SP), Brasil.

Orcid: https://orcid org/0000-0003-02604062

igorfuser@gmail.com

\section{América Latina: progressismo, retrocesso e resistência}

\author{
Latin America: progressivism, retraction, and resistance \\ Igor Fuser ${ }^{1}$ \\ DOI: $10.1590 / 0103-110420185307$
}

RESUMO O artigo examinou a crise dos chamados 'governos progressistas' latino-americanos como parte de um processo político regional em que as elites dominantes locais se aliam aos Estados Unidos em uma ofensiva política para bloquear o acesso de forças de esquerda ao Poder Executivo em toda a região. Argumenta-se que governos tão díspares quanto os de Lula no Brasil, de Chávez na Venezuela, de Morales na Bolívia e do casal Kirchner na Argentina, entre outros, possuem fortes traços em comum, entre os quais: o fortalecimento do papel do Estado na economia, a ênfase nas políticas sociais e a busca de maior autonomia externa. Esses projetos se mantiveram por sucessivos mandatos presidenciais e proporcionaram avanços sociais significativos, mas terminaram por entrar em crise, em um processo atribuído, em parte, tanto às limitações inerentes a essa opção política quanto às pressões do imperialismo estadunidense e seus aliados. Ao final, descarta-se a noção de 'fim de ciclo' e aponta-se a dificuldade de consolidação de projetos liberais-conservadores como alternativa às experiências progressistas na região.

PALAVRAS-CHAVE América Latina. Política. Governo.

ABSTRACT The article examined the crisis of so-called Latin American 'progressive governments' as part of a regional political process in which the dominant local elites ally with the United States in a political offensive to block the access of leftist forces to the executive branch throughout the region. It is argued that governments as disparate as Lula's in Brazil, Chávez's in Venezuela, Morales's in Bolivia, and the Kirchner couple in Argentina, among others, have strong features in common, among which: strengthening the role of the state in the economy, the emphasis on social policies, and the search for greater external autonomy. Those projects continued through successive presidential mandates and provided significant social advances, but ended up in crisis, in a process attributed in part both to the limitations inherent to this political option and to the pressures of US imperialism and its allies. In the end, the notion of 'end of cycle' is discarded and the difficulty of consolidating liberal-conservative projects as an alternative to the progressive experiences in the region is pointed out.

KEYWORDS Latin America. Politics. Government. 


\section{Introdução}

A derrubada da presidenta Dilma Rousseff e a perseguição judicial ao ex-presidente Luiz Inácio Lula da Silva, marcos políticos do retrocesso autoritário e elitista em curso no Brasil, só podem ser entendidos no contexto mais amplo da ofensiva liberal-conservadora contra governos progressistas, personalidades de esquerda e movimentos populares em toda a América Latina. Na Argentina, a ex-presidente Cristina Kirchner também é alvo de uma tentativa de criminalização, com acusações tão inconsistentes quanto as lançadas contra Lula. Ataques semelhantes são desfechados contra o ex-presidente do Equador, Rafael Correa, e contra o vice-presidente eleito naquele país em 2016, Jorge Glas, posteriormente destituído e encarcerado em um processo judicial com evidentes sinais de parcialidade. Em todos esses processos, nota-se o protagonismo exercido por atores políticos que têm em comum a ligação com os setores sociais e econômicos dominantes nos respectivos países durante todo o século XX, para não retroceder mais do que isso no nosso olhar para a história: as camadas superiores do Judiciário, os proprietários das grandes empresas de comunicação, os acionistas de várias das maiores empresas no âmbito nacional. Mais do que isso, também se verifica a sintonia entre esses atores e as posições da política externa dos Estados Unidos da América (EUA), de distanciamento em relação aos governos frequentemente qualificados no discurso político estadunidense como 'populistas' e, em casos como o da Venezuela, de confronto aberto. Claramente, todos os fatos acima mencionados se inserem de um mesmo processo político regional, movido pela intenção de encerrar um período muito específico na história contemporânea latino-americana.

Durante um intervalo de pouco mais de 15 anos, entre janeiro de 1999, quando se inaugurou na Venezuela o primeiro mandato presidencial de Hugo Chávez, dando início à chamada Revolução Bolivariana, e dezembro de 2015, data do triunfo da coligação direitista liderada por Mauricio Macri na Argentina, encerrando a sequência de governos ligados ao peronismo de esquerda, a América Latina e, especialmente, a América do Sul destacaram-se no cenário internacional pela presença de um conjunto de governos que desafiaram as orientações políticas e econômicas emanadas no centro do sistema capitalista mundial. Nesse período, que alguns autores denominam de 'a onda rosa', a busca de melhoria das condições de vida das maiorias desfavorecidas, de maior autonomia no cenário internacional e da retomada de ideais desenvolvimentistas passou a dar a tônica para as políticas públicas e para a inserção externa de um grupo de países que inclui, além dos já citados (Brasil, Argentina, Equador e Venezuela), também Uruguai, Bolívia, Paraguai, Nicarágua e El Salvador, aos quais vieram a se somar Cuba - com um regime e trajetória histórica muito diferentes - e, em alguma medida, Chile nos mandatos presidenciais da presidenta Michelle Bachelet ${ }^{2,3}$.

Algumas dessas experiências políticas já foram encerradas, seja pela via eleitoral, seja por meio de golpes jurídico-parlamentares, enquanto os governos progressistas remanescentes se veem sob forte assédio dos seus opositores internos e de um poderoso opositor externo, o governo dos EUA. Em todos esses países, as alianças antiesquerdistas apresentam a mesma configuração social: a elite do Poder Judiciário, os grandes grupos empresariais de mídia, as principais organizações patronais, segmentos importantes das classes média e média-alta (o que garante a presença de manifestantes nas ruas em número suficiente para dar a esse movimento uma dimensão de massas) e os religiosos conservadores, tudo isso com o apoio das autoridades e de aparatos privados estadunidenses.

Os métodos de ação são semelhantes: o uso intensivo do escândalo político, as denúncias sem provas, a desconstrução gradativa da legitimidade do governo pela exploração midiática de todas as brechas possíveis. Não se discutem projetos de longo alcance ou concepções ideológicas; a 
avaliação dos resultados das ações estatais raramente aparece. A agenda pública é intoxicada por notícias falsas, rumores, preconceitos, pela reciclagem dos velhos clichês ideológicos da Guerra Fria. Na Bolívia, em fevereiro de 2016, por ocasião do referendo convocado pelo presidente Evo Morales para decidir sobre sua possibilidade de concorrer a mais um mandato além dos previstos pela Constituição, a mídia fabricou um escândalo para prejudicá-lo. Atribuiu ao presidente um filho que não existia. Quando, finalmente, ficou claro que tudo não passava de uma grande mentira, já era tarde Morales havia sido derrotado no referendo por uma pequena margem de votos ${ }^{4}$.

A semelhança de métodos e de atores, a coincidência temporal, a onipresença dos agentes dos EUA em cada episódio de mudança ou tentativa de mudança de orientação política na América Latina, tudo isso permite supor a existência de uma ofensiva política que se realiza além-fronteiras, movida por um conjunto de objetivos comuns: a) remover os governos progressistas instalados a partir da virada do século; b) deslegitimar aos olhos da população as lideranças, os partidos políticos e os movimentos sociais associados a esses governos; c) blindar as instituições do Estado para impedir o regresso de atores políticos de esquerda ao comando do Poder Executivo e seu acesso a posições de influência efetiva no Legislativo; d) aplicar de modo irrestrito e em ritmo acelerado as políticas neoliberais em sua versão mais extrema; e) facilitar o acesso das empresas estrangeiras ao mercado interno e, especialmente, aos recursos naturais de cada país; f) realinhar a diplomacia latino-americana aos interesses dos EUA.

Uma definição bastante precisa da atual ofensiva direitista é que a fez, em entrevista ao autor deste artigo, o analista político cubano Roberto Regalado ${ }^{5}$. Polemizando com a interpretação bastante difundida de que estamos diante do 'fim do ciclo progressista'. Regalado admite que presenciamos, sim, o fim de um período histórico na região, mas em termos bem diferentes daqueles utilizados pelo pensamento hegemônico. O que está terminando, segundo ele, é

um período em que a esquerda ocupa determinados espaços na institucionalidade democrática burguesa e instala governos com traços bonapartistas, por meio dos quais as forças populares conseguem fazer avançarem suas próprias causas. Hoje em dia esse espaço não existe mais. Mudou a correlação de forças que permitiu um Estado bonapartista hoje cada vez menos viável. Existem, é claro, diferenças de país para país, uns que avançaram mais, outros menos. Mas, como tendência geral, o que se percebe é que a direita e o imperialismo conseguiram reduzir os espaços democráticos que nós tínhamos conseguido abrir. Já não estão dispostos a se alternar no governo com a esquerda. [...] Trata-se de expulsar a esquerda dos espaços institucionais e, em particular, do Poder Executivo, e de liquidá-la. Expulsar, fechar a porta e jogar fora a chave, para que não regresse nunca mais. É para isso que promovem toda essa campanha de criminalização dos nossos líderes 5 .

Diante de uma ofensiva de tal agressividade, impõe-se às correntes democráticas e populares o desafio de preservar os espaços políticos conquistados, defender os governos progressistas, recuperar os espaços institucionais e criar condições para novos avanços. Para as classes dominantes locais e para o imperialismo, ao contrário, trata-se de levar até o fim o projeto de destruição política da esquerda latino-americana.

\section{Foco nas políticas sociais e na busca da autonomia externa}

Para entender o que está em jogo, é necessário caracterizar com clareza os governos aqui denominados como 'progressistas'. 
Antes, porém, vale a pena assinalar qual é o entendimento adotado sobre dois termos que perpassam o presente artigo. 'Progressismo' é uma palavra constante no discurso político das esquerdas desde a primeira metade do século $\mathrm{XX}$, no sentido de designar os atores políticos favoráveis ao que se costuma chamar de 'transformação social', em contraposição ao conservadorismo e ao elitismo, geralmente associados às posições da direita ${ }^{6}$. Refere-se à ideia de 'progresso social', interpretada como a conquista de níveis crescentes de bem-estar para a maioria da população, ampliação dos direitos sociais e igualdade no exercício dos direitos políticos, desenvolvimento econômico, usufruto das riquezas naturais a partir de critérios de soberania nacional. Para o conceito de 'esquerda', a referência aqui utilizada tem como base a sintética definição de Norberto Bobbio, erigida sobre a dicotomia igualdade/desigualdade. Segundo o filósofo italiano, são 'de esquerda' os que encaram a igualdade como um valor primordial, enquanto o campo da 'direita' seria constituído pelos que priorizam a desigualdade, valorizada como algo positivo ${ }^{7}$.

Pontos comuns marcam os objetivos de todas as gestões governamentais progressistas na América Latina. No plano econômico, busca do crescimento econômico, redução da dependência, ampliação do mercado interno. No plano social, políticas públicas voltadas para a inclusão, redução da pobreza e da desigualdade, melhoria geral das condições de vida. Tudo isso sem romper com as classes dominantes internas nem com o sistema econômico internacional.

As gestões progressistas - tanto nas suas versões mais radicais quanto nas mais moderadas - compartilham a ideia de que é necessária uma forte presença estatal na economia para promover e orientar o desenvolvimento econômico e social ${ }^{8}$. Nesse ponto, diferem totalmente do neoliberalismo, que prioriza o mercado e minimiza o setor público (exceto quando se trata de reprimir as classes subalternas e de recorrer a dinheiro público para salvar um ou outro setor empresarial contra os azares do mercado). Outro destaque em todas as gestões progressistas é o esforço para recuperar o controle estatal sobre os recursos econômicos naturais, especialmente o petróleo e o gás. Esses governantes colocaram em prática políticas sociais de alta intensidade, com redistribuição (limitada) da renda, valorização do trabalho e 'inversão das prioridades', favorecendo os investimentos públicos em saúde, educação, moradia e infraestrutura, em benefício das camadas populares. Em política externa, destacaram-se pela busca de maior autonomia, em uma postura que teve como marco a rejeição, em 2005, do projeto estadunidense da Área de Livre-Comércio das Américas (Alca), encarada como uma tentativa de 'recolonização'. Aproximaram-se das duas potências que rivalizam com os EUA na cena global - a China e a Rússia -; e o Brasil chegou a formar com outros países o Brics, principal referência na busca do multilateralismo no sistema internacional.

Todos esses países com governos progressistas passaram por longos períodos de forte crescimento econômico. O que se pode discutir é em que medida esses bons resultados se devem ao contexto global favorável, graças ao ciclo de altos preços das commodities agrícolas, minerais e energéticas na maior parte da década de 2000 , e qual foi o grau de influência da ampliação do mercado de consumo doméstico. Esses governos contabilizam, no plano social, grandes avanços em educação, saúde, moradia, transporte, salários, redução da pobreza e da fome uma medida definitiva para avaliar o quanto foram vitoriosos. Em contraste com a Europa e com a América do Norte, onde se leva a cabo a sistemática destruição das conquistas e benefícios do 'Estado do bem-estar social', na América Latina, as gestões de esquerda promovem a ampliação dos direitos dos trabalhadores e, em geral, da maioria desfavorecida. Ao contrário do prognóstico dos céticos que previam vida curta para os presidentes oriundos do campo popular, seus projetos 
políticos - com exceção do caso do Paraguai - mostraram uma admirável longevidade, com sucessivas reeleições (individuais ou do bloco político no poder, como ocorreu no Uruguai), sempre em pleitos limpos e de legitimidade incontestável.

Os governos progressistas podem ser classificados em dois campos claramente distintos9 $^{9}$. De um lado estão os governos orientados por uma perspectiva revolucionária ou socialista, agrupados na Aliança Bolivariana para as Américas (Alba), o projeto de integração regional impulsionado pela Venezuela. Esses governos apresentam uma atuação política marcada pelo confronto com o imperialismo estadunidense e com as elites domésticas. Enfatizam o protagonismo popular no cotidiano da política (ao menos na retórica) e têm a particularidade de terem elaborado, no seu período inicial, Constituições chamadas de 'refundadoras', o que, como a palavra indica, expressa o entendimento de cada uma das três respectivas repúblicas (Venezuela, Bolívia e Equador) foram incapazes de proporcionar uma verdadeira cidadania à maioria da população e que, portanto, permaneceram incompletas daí a necessidade de serem, simbolicamente, recriadas, como que a partir do zero.

No outro campo, situam-se dos governos que podem ser chamados de neodesenvolvimentistas (Brasil, Uruguai, Argentina, Paraguai e, segundo alguns critérios, Chile). Suas políticas se estruturam a partir de alguma ideia de conciliação de classes. Em política externa, são mais pragmáticos na relação com as potências ocidentais, em especial com os EUA. Em lugar do socialismo, propõem-se a melhorar o sistema vigente. No caso da Argentina, o discurso dos Kirchner propunha a construção de um 'capitalismo sério' (partindo do princípio de que o praticado por seus antecessores não o era).

Apesar de suas diferenças, 'refundadores' e 'neodesenvolvimentistas' se apoiam ou apoiaram mutuamente em todo o período, articulando-se em projetos de integração regional como a União das Nações da América do Sul (Unasul), a Comunidade dos Estados da América Latina (Celac) e o Conselho de Defesa Sul-Americano (CDS), além a ampliação do Mercado Comum do Sul (Mercosul), para incluir a Venezuela, a Bolívia e o Equador - o que se concretizou apenas no primeiro caso.

A existência simultânea de vários governos de esquerda e de centro-esquerda na América Latina apresenta um significado histórico extraordinário. Em primeiro lugar, trata-se de um desafio aberto à hegemonia dos EUA. Durante todo o século XX, desde a Guerra Hispano-Americana, a América Latina se destaca como a única região do globo em que a supremacia estadunidense se exerceu de modo uniforme, praticamente desimpedida, sem a presença de atores internos ou externos com capacidade política para fazer frente à preponderância da grande nação do Norte nas esferas política, econômica e cultural' ${ }^{10}$. A Grã-Bretanha, antiga potência hegemônica, retirou-se gradualmente de cena ao longo do século, acompanhando sua trajetória de declínio global; a Alemanha nazista fracassou em seus esforços de conquistar aliados na região; e a influência da União Soviética permaneceu restrita à dos partidos comunistas a ela alinhados, em níveis muito modestos, apesar da histeria direitista sobre o 'perigo vermelho'. Nesse cenário, Cuba é a exceção que confirma a regra. Eis que, na contramão do discurso hegemônico do 'fim da história', em meio ao avanço da globalização neoliberal impulsionada a partir de Washington e de Wall Street, países latino-americanos que juntos representam a maior parte do território e da população desta parte do mundo declaram superada a Doutrina Monroe e anunciam a disposição de orientar sua conduta internacional com base em critérios de independência e soberania"1".

Igualmente, no plano interno, as elites dominantes latino-americanas, herdeiras do colonialismo ibérico e dos regimes de trabalho escravocrata e servil, veem-se em uma situação inédita em que não mais detêm as 
rédeas do poder. As novas lideranças instaladas no comando do Executivo expressam, claramente, sua ligação com as camadas subalternas da sociedade, seja pelos vínculos políticos, seja pela origem étnica ou social. Lula, um ex-operário, nasceu em uma família de retirantes nordestinos. Morales, líder dos plantadores de coca da Bolívia, é filho de indígenas. Semelhantemente, o venezuelano Chávez descende de brancos, negros e índios; é filho de uma professora primária. Mesmo nos casos em que os governantes provêm da 'elite branca', sua trajetória política se vincula a instrumentos de representação das demandas populares na esfera pública: o partido peronista (Néstor e Cristina Kirchner), a Frente Ampla uruguaia (Tabaré Vázquez e Pepe Mujica), o catolicismo popular da Teologia da Libertação (o presidente deposto do Paraguai, Fernando Lugo), a intelectualidade antioligárquica (o economista equatoriano Rafael Correa).

Todos eles foram eleitos em contendas políticas caracterizadas como expressão de um conflito social definido a partir da dicotomia pobres/ricos. Não por acaso, os presidentes progressistas obtiveram apoio amplamente majoritário nas faixas sociais de renda mais baixa, em contraste com a rejeição e com índices menores de apoio entre os eleitores das camadas sociais privilegiadas. Tampouco é casual a postura hostil que a mídia dominante em todos esses países adotou contra essas lideranças e suas respectivas organizações partidárias, situadas à esquerda do espectro político. Os governos progressistas foram ou são alvos permanentes de campanhas virulentas das elites dominantes locais. Por toda parte, os atores políticos situados no campo conservador deixaram claro seu inconformismo com o novo estado de coisas e se mobilizaram para debilitar os governantes de esquerda ou centro-esquerda, seja com o uso sistemático dos meios de comunicação para apresentá-los de modo negativo, seja com o recurso de meios ilegais para afastá-los do poder (com sucesso, em alguns casos, e fracasso, em outros).

\section{Limites e vulnerabilidades da experiência progressista}

Mesmo com os pontos fortes acima mencionados, os governantes da 'onda rosa' logo deixaram visíveis vulnerabilidades que abriram espaço para a atual ofensiva liberal-conservadora. As limitações têm a ver, antes de tudo, com a própria origem dessas experiências políticas. Com a única exceção dos socialistas chilenos (melhor seria chamá-los de social-democratas), a chegada da esquerda aos governos ocorre como uma reação do eleitorado ao fracasso das políticas neoliberais da década de 1990 em proporcionar melhorias econômicas e sociais. Mesmo nos países onde as propostas do Consenso de Washington obtiveram sucesso em conter a hiperinflação, os bons resultados iniciais logo se diluíram diante do cenário sombrio que marcou o final do século XX na região, com baixos índices de crescimento, desindustrialização, aumento do desemprego e da exclusão social, agravamento das desigualdades e desmanche das estruturas de proteção social, que já eram precárias.

As maiorias desprivilegiadas se viram abandonadas à sua própria sorte, sem poder contar com o Estado como instrumento de proteção. A dramática derrubada do presidente argentino Fernando de la Rúa, em dezembro de 2001, simboliza, mais do que qualquer outro evento, o colapso das elites políticas tradicionais, incapazes de atender às demandas da sociedade e, em particular, de suas camadas mais pobres. Na maré de insatisfação que varreu a América do Sul, os partidos políticos ligados ao modelo neoliberal foram afastados do poder em todos os países, com exceção da Colômbia e do Chile.

Uma limitação mais concreta decorre do fato de que os governos progressistas se constituíram por meio de eleições, ao contrário, por exemplo, do regime cubano, fruto de uma revolução armada vitoriosa. Em alguns casos, a vitória eleitoral das forças de esquerda na América Latina foi precedida de uma 
sublevação popular, em outros, não. Contudo o elemento comum, sempre, é a aceitação dos métodos da democracia representativa, ainda que com a inclusão eventual de elementos da democracia participativa e, na maioria dos países, com a presença de uma forte dose de personalismo no exercício do poder e o reforço das capacidades do Executivo. Em nenhum país, os governos progressistas conseguiram superar - nem sequer alterar significativamente - as estruturas econômicas existentes desde o período colonial. Permaneceram, todos os países envolvidos na 'onda rosa', a exercer um papel subalterno na divisão global do trabalho - o de exportadores de bens primários e importadores de mercadorias mais sofisticados, sobretudo produtos industriais ${ }^{12}$.

Do ponto de vista político, os governos progressistas, apesar de serem permanentemente acusados de 'autoritários' pela oposição direitista e pelos EUA, pouco avançaram no controle daqueles aparatos que constituem, na visão dos autores marxistas, os instrumentos essenciais para o exercício do poder burguês. A mídia permaneceu nas mãos da classe dominante; e a burocracia do Estado, de modo geral, manteve-se à margem do esforço de transformação da sociedade, adotando, em certos casos, uma atitude hostil e, até mesmo, golpista. Nem sempre os presidentes tiveram ao seu lado maiorias estáveis no Legislativo tampouco, com exceção da Venezuela, foram capazes de controlar o Judiciário.

O foco da gestão governamental nas eleições representou, ao mesmo tempo, uma vantagem e uma desvantagem para a esquerda sul-americana nessa experiência recente. As maiorias eleitorais, sem dúvida, foram decisivas para conferir legitimidade aos governos progressistas, de tal modo que, mesmo diante dos mais ferozes ataques, sempre foi possível aos seus defensores responderem: 'Esse é um governo democrático, eleito livremente pelo povo'. Por outro lado, a dependência da dinâmica eleitoral, com a necessidade de ganhar todas, absolutamente todas as muitas eleições, impôs limites rígidos às possibilidades de planejamento, obrigando os governos a se reger por uma lógica de curto-prazo, imediatista. Para derrotar seus adversários em eleições sempre competitivas, algumas delas duríssimas, era necessário oferecer à população sempre benefícios concretos nos prazos mais curtos possíveis, o que, certamente, inviabilizou projetos de reforma estrutural de maior alcance e duração - e que talvez alienassem partes da base de apoio eleitoral oficialista. Ao comentar o conjunto de políticas sociais implementadas por Chávez, Hetland ${ }^{\mathbf{1 3}}$ afirma que a maior parte dos projetos voltados para redução da pobreza, da desigualdade e da exclusão social era financiada pela empresa petrolífera estatal (PDVSA), que, para financiar essas ação, foi obrigada a abrir mão de boa parte das receitas que originalmente haviam sido destinadas para investimentos com o objetivo de aumentar sua eficiência e introduzir novas tecnologias.

Também em referência ao caso da Venezuela, Edgardo Lander, uma das vozes mais críticas aos governos progressistas em uma perspectiva de esquerda, avalia que a valiosa receita petroleira obtida durante o governo de Chávez representou, ao mesmo tempo, um fator de força para o processo político naquele país e uma limitação para as possibilidades de transformação radical da sociedade:

No curto prazo, a renda petroleira facilitou a legitimidade e estabilidade política em condições extraordinariamente adversas, tornou possíveis as missões e demais políticas públicas e financiou sucessivas iniciativas internacionais de alto impacto. Mas isto se faz ao custo de reforçar a cultura rentista centrada no Estado. [...] Esse modelo contribui para reforçar um padrão de consumo maciço de hidrocarbonetos que é incompatível tanto com a possibilidade de uma alternativa radical ao modelo civilizatório e produtivo hegemônico da sociedade capitalista, bem como com a preservação das condições que fazem possível a vida no planeta Terra' ${ }^{14(66-67)}$. 
Os governos progressistas falharam também naquilo que o jargão de esquerda chama de 'luta de ideias'. Não houve um empenho oficial (ao menos em um nível que pudesse ser considerado satisfatório) para associar as inegáveis conquistas e avanços sociais com a orientação política dos governantes. A população mais pobre, a grande beneficiária das iniciativas no campo social, permaneceu em posição passiva, a de recebedora dos benefícios, sem participar das decisões nem se envolver em debates capazes de proporcionar um grau maior de consciência sobre as questões políticas relacionadas com esse ou aquele programa governamental. Em texto publicado a partir da experiência de ambos os autores na Bolívia, Paula Klachko e Katu Arkonada afirmam que

Os governos progressistas redistribuíram a riqueza sem politização social [...]. As classes médias de origem popular não encontraram alternativa, ao elevar seus níveis de renda e de consumo, além do American way of life, ou cultura do shopping. O ciclo progressista não conseguiu derrotar a hegemonia do capitalismo no plano cultural, e uma vez que as classes populares alcançam níveis de consumo que até pouco tempo atrás pertenciam a outras classes sociais, acabam interiorizando as

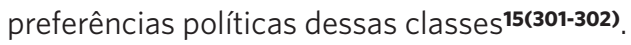

No Brasil, às vésperas da eleição presidencial de 2014, uma pesquisa com pessoas de baixa renda que, indiscutivelmente, melhoraram de situação, seja por aumento no salário real, seja pela participação em programas de governo que democratizaram o acesso à universidade, pediu aos entrevistados que apontassem qual foi o fator decisivo para a sua melhoria de vida. As três principais respostas, pela ordem, foram as seguintes: 'Deus', 'minha família' e 'meu esforço pessoal' ${ }^{16}$.

Outro problema diz respeito à burocratização, ineficiência, despreparo para o exercício de funções de gestão pública. Há ainda a presença de um forte personalismo em quase todas essas experiências políticas. O papel decisivo de lideranças carismáticas (Lula, Néstor \& Cristina Kirchner, Evo Morales, Chávez) garantiu a unidade política de um amplo leque de grupos, indivíduos, partidos e movimentos sociais em torno de projetos audaciosos de transformação ${ }^{17}$. Ademais, a confiança de amplos setores da população nos governantes de esquerda sempre foi inseparável da confiança depositada na pessoa de cada um desses líderes: sem eles, nada do que ocorreu teria sido possível. Por outro lado, os militantes e dirigentes acabaram por se tornar dependentes de lideranças literalmente insubstituíveis. Outrossim, o processo político de esquerda nesses países foi afetado pelo fato de que esses líderes são humanos - cometem erros, são incapazes de saber tudo e de estar em todos os lugares ao mesmo tempo e, de vez em quando, morrem.

\section{Burguesias locais, protagonistas do retrocesso}

A ação intervencionista dos EUA com o objetivo de reverter a onda progressista na América Latina é um fato objetivo, amplamente comprovado por documentos. Entretanto, o papel do imperialismo não anula o protagonismo das classes dominantes locais nos esforços - bem-sucedidos em alguns países; em outros, nem tanto - para expulsar a esquerda dos espaços conquistados no poder estatal ${ }^{5}$. Nenhum país latino-americano foi invadido, como o Iraque ou a Líbia. Em todos os casos verificados até agora, o conflito político em torno da manutenção ou remoção dos governos progressistas se apresenta como um conflito interno, uma realidade que pode se modificar no futuro imediato, a depender dos desdobramentos da ostensiva ingerência estadunidense na Venezuela, que envolve até mesmo ameaças de intervenção militar proferidas pelo presidente Donald Trump e por alguns de seus auxiliares. 
O que ocorreu no Brasil é bastante expressivo. O golpe jurídico, midiático e parlamentar de 2016 atropelou as ilusões de quem acreditava nas virtudes infinitas da política de conciliação de classes - a ideia de que seria possível superar o apartheid social e o subdesenvolvimento econômico sem confronto com as elites dominantes, mas apenas por meio do crescimento da economia. Verificou-se, na prática, uma notável coesão das classes dominantes no golpe contra o governo legítimo de Dilma Rousseff. Com a óbvia exceção dos empreiteiros da engenharia pesada, envolvidos judicialmente na Operação Lava Jato - que claramente inclui entre os seus objetivos a destruição desse setor estratégico da economia nacional, o que se viu na mobilização pelo impeachment foi um verdadeiro quem-é-quem da burguesia brasileira. Lá estavam, unidos ao redor da palavra de ordem 'fora Dilma', os banqueiros, os barões do agronegócio, os magnatas da mídia, os caciques da indústria brasileira remanescente, lado a lado com agrupamentos fascistas, os políticos de duvidosas credenciais éticas e os expoentes de um Judiciário dominado pela extrema-direita.

$\mathrm{Na}$ vanguarda, marchava a influente Federação das Indústrias do Estado de São Paulo (Fiesp), justamente a entidade que, ao longo da história brasileira, desempenhou o papel de principal porta-voz de uma burguesia 'nacional' ou 'interna'. A adesão maciça do empresariado surpreendeu os intelectuais que atribuíam a longevidade dos governos liderados pelo Partido dos Trabalhadores (PT) a uma suposta 'frente neodesenvolvimentista', formada a partir da convergência de interesses entre os trabalhadores e setores da burguesia supostamente em 'contradição' com o capital externo ${ }^{18}$. Esses empresários, na maioria do setor industrial, favorecidos com linhas de crédito e com todo tipo de apoio oficial, amealharam, de fato, lucros fabulosos no ciclo de governos progressistas no Brasil, especialmente no governo Lula. Porém, quando veio o governo
Rousseff e surgiram dificuldades econômicas ligadas à crise internacional, esses empresários em lugar de darem apoio (aos projetos oficiais) foram progressivamente se afastando do governo, como se cada gesto para efetivar o rol de medidas por eles mesmos propostos, fizesse crescer o temor do 'estatismo', criando desconfiança, avalia Singer ${ }^{19}$. Em suma, a burguesia local aceitou todas as benesses, pressionou (em geral, com sucesso) por vantagens setoriais aqui e ali. No entanto, no campo político se limitou, no máximo, a tolerar os governos 'de esquerda' como uma extravagância temporária em uma trajetória histórica de cinco séculos de poder irrestrito da elite dominante. Quando surgiu a oportunidade, agiu em bloco para golpear a democracia, conforme assinala a obra coletiva publicada pela Fundação Perseu Abramo, do PT, em que faz um balanço do golpe de 2016: "Cada um dos setores da elite contemplados por políticas no início do governo Dilma acabou por voltar-se contra ele"16(69).

Tal conduta não é exclusiva da burguesia brasileira, mas se reproduz país por país, com mínimas variações. Na Argentina, por exemplo, a vitória eleitoral de Macri foi impulsionada por uma aliança que envolve o amplo leque das classes dominantes daquele país, inclusive os setores que haviam sido amplamente beneficiados pelas políticas neodesenvolvimentistas dos governos dos Kirchner. O golpismo da burguesia pode ser explicado por sua opção estratégica pela associação com o capital externo e pela renúncia a qualquer projeto autônomo de desenvolvimento nacional e regional, conforme analisa' ${ }^{19}$. Após três décadas de um incessante processo de desnacionalização econômica, as burguesias latino-americanas se mostram atualmente plenamente dispostas a se adaptarem a uma divisão internacional do trabalho que relega aos países da região o papel de fornecedores de matérias-primas agrícolas e minerais e de serviços energéticos para as economias do centro do sistema capitalista, com a integração subalterna 
das remanescentes indústrias da região às cadeias produtivas globais. Do ponto de vista desses empresários, já não há um projeto nacional a implementar ou defender.

Nesse contexto, articula-se o discurso do 'fim do ciclo progressista' como um instrumento retórico funcional à ofensiva política liberal-conservadora. O viés determinista dessa ideia é evidente. Quem aceita que já não existem condições para a instalação de governos de esquerda e, particularmente, governos com a agenda de reformas sociais e soberania política implementada nos países da 'onda rosa' está condenado a esperar passivamente, com resignação fatalista, por um algum momento, em um futuro indefinido, em que se abram novamente as condições para um novo ciclo de mudanças sociais.

O discurso do 'fim de ciclo', ideológico no pior sentido do termo, apresenta também um grave problema lógico. Se o que caracteriza um ciclo político é a existência de uma determinada agenda política, um contexto específico e atores políticos definidos a partir desses elementos, quais seriam os tópicos definidores de um novo ciclo pós-progressista? Para o sociólogo e vice-presidente boliviano Álvaro García Linera,

O fim de ciclo constitui o aborto ideológico dessa teleologia história que pretende fazer crer que as sociedades se movem sob o impulso de leis independentes e por cima das próprias sociedades, na forma de princípios quase-religiosos que pretendem explicar a dinâmica do mundo. [...] Ao se colocar o 'fim de ciclo' como algo inelutável e irreversível se busca mutilar a práxis humana como motor do próprio futuro humano e fonte explicativa da história, lançando a sociedade à impotência de uma contemplação derrotista perante acontecimentos que, supostamente, se situam à margem da própria ação humana²0.

Concretamente, na América Latina do presente momento, o grande embate político e social em curso é, no essencial, o mesmo desde o início da década de 1990, quando se colocou em marcha o projeto neoliberal do Consenso de Washington. Os grandes conflitos se definem, desde então, ao redor da privatização das empresas estatais ou do seu fortalecimento como agentes a serviço do interesse público, da expansão ou da restrição das políticas sociais e dos serviços prestados pelo Estado à sociedade, da inserção subordinada no capitalismo global ou da busca de algum tipo de desenvolvimento nacional em bases soberanas. Essas clivagens se mantêm como elemento permanente da nossa época, muito além dos resultados circunstanciais das eleições, da remoção ou da manutenção de determinados atores à frente do Executivo.

Cabe perguntar, diante disso: qual é o projeto dos direitistas que recuperaram recentemente o controle de alguns governos nacionais e dos empresários que lhes dão sustentação política? A resposta é simples: aprofundar o neoliberalismo e a submissão aos EUA e ao capitalismo global. Em síntese, uma agenda indefensável socialmente, propostas 'impopulares' que necessitam ser escondidas durante os embates eleitorais, dado o repúdio que inevitavelmente geram. Ao contrário do que ocorria três décadas atrás, a ideia da 'globalização' já não se mostra atraente às multidões de latino-americanos, portadores de amargas lembranças dos governos neoliberais do passado recente. "Não há projeto, o que há são construções do discurso aproveitando as debilidades e erros cometidos pelos governos de esquerda"15(300). De fato, a direita só tem a oferecer às nossas sociedades o agravamento da miséria e da desagregação social, a concentração ainda maior da riqueza, um cenário tenebroso de desemprego, ignorância, violência e caos.

Certamente, o período político que se encerrou na nossa região é outro - aquele tempo em que a esquerda ainda conseguia governar mediante um convívio relativamente pacífico com a burguesia e com o imperialismo; o tempo em que havia alguma margem para a conciliação de classes, para 
as mudanças sem confronto nem ruptura. Essa época ficou para trás, como se depreende das sucessivas incursões do 'golpismo suave', do lawfare, da criminalização dos movimentos sociais, da perseguição a políticos, ativistas e intelectuais de esquerda, da sabotagem econômica doméstica e internacional, das ameaças (por enquanto, só ameaças) de intervenção militar sob o comando e estímulo dos EUA.

Nesse sentido, sim, é que só pode falar do fim de um 'ciclo'. O tempo passado das mudanças políticas em clima de 'paz e amor' ficou definitivamente para trás; e o desafio das esquerdas, agora, é encontrar novos caminhos para a resistência, nas ruas, nas disputas eleitorais, nos locais de trabalho e moradia, na luta de ideias e até, na medida do possível, nos espaços ainda se mostrar possível o exercício do governo; porque a história não se repete, e nada será como antes.

\section{Referências}

1. Panizza F. El Populismo como Espejo de la Democracia. Buenos Aires: Fondo de Cultura Económica; 2009.

2. Harnecker M. Inventando para No Errar: América Latina y el socialismo Del siglo XXI. Caracas: Centro Internacional Miranda; 2010.

3. Burbach R, Fox M, Fuentes F. Latin America's Turbulent Transitions the future of the twenty-first socialism. New York: Fernwook Publishing; Zed Books; 2003.

4. Ferreira R. Caso Zapata la confabulación de la mentira. Santa Cruz de la Sierra: El País; 2016.

5. Regalado R. "Fim de ciclo para a esquerda na América Latina?”. Entrevista. Outras Palavras [internet]. 2018 ago [acesso em 2018 ago 30]. Disponível em: https://outraspalavras.net/mundo/america-latina/ fim-de-ciclo-para-a-esquerda-na-america-latina/.

6. Silva FP. Democracias Errantes reflexões sobre ex- periências participativas na América Latina. Rio de Janeiro: Ponteio; 2015.

7. Bobbio N. Direita e Esquerda razões e significados de uma distinção política $2^{\text {a }}$ ed. São Paulo: Unesp; 2001.

8. Ayerbe LF. Novos atores políticos e alternativas de governo: os casos de Argentina, Bolívia, Brasil e Venezuela. In: Ayerbe LF organizador. Novas Lideranças Políticas e Alternativas de Governo na América do Sul. São Paulo: Unesp; 2008. p. 265-302.

9. Katz C. El Rediseño de América Latina: Alca, Mercosur y Alba. Buenos Aires: Luxembourg; 2006.

10. Santos M. O Poder Norte-Americano e a América Latina no Pós-Guerra Fria. São Paulo: Annablume; 2007.

11. Sader E. A Nova Toupeira os caminhos da esquerda latino-americana. São Paulo: Boitempo; 2009. 
12. Alonso AA, Alonso AA. Las promesas del extrativismo en América Latina: Luces y sombras. In: Carrilo Nieto JJ, Escárzaga F, Gunther MF, coordenadores. Los Gobiernos Progresistas Latinoamericanos contradiciones, avances y retrocesos. México: Universidad Autónoma Metropolitana, Ítaca, 2016. p. 31-62.

13. Hetland G. Why Is Venezuela in Crisis [internet]. 2017 ago [acesso em 2018 ago 24]. Disponível em: https://www.thenation.com/article/why-is-venezuela-in-crisis/.

14. Lander E. Venezuela: logros y tensiones em los primeros ocho años del proceso de cambio. In: Stolowicz B. Coordenador. Gobiernos de Izquierda en América Latina un balance político. Bogotá: Aurora; 2007. p. 39-76.

15. Klachko P, Arkonada K. As Lutas Populares na América Latina e Os Governos Progressistas crises e desafios da atualidade. São Paulo: Expressão Popular; Fundação Perseu Abramo; 2017.

16. Fundação Perseu Abramo. Brasil 2016 Recessão e Golpe. São Paulo: Fundação Perseu Abrama; 2017.
17. Raby D. El liderazgo carismático en los movimientos populares y revolucionarios. Cuad. Cendes. 2006 maio-ago; 26(62):61-74.

18. Boito Júnior A. As contradições da frente neodesenvolvimentista. 2012 mar; [acesso em 2018 ago 25]. Disponível em: http://www.viomundo.com. br/politica/armando-boito-jr-as-contradicoes-da-frente-neodesenvolvimentista.html.

19. Mattos MB. O capitalismo no Brasil contemporâneo. 2017 fev [acesso em 2018 set 2018]. Disponível em: http://blogjunho.com.br/o-capitalismo-no-brasil-contemporaneo/.

20. Linera AG. ¿¿Fin de ciclo progresista o proceso por oleadas revolucionarias?. 2017 jun [acesso em 2018 set 24]. Disponível em: https://www.vicepresidencia.gob.bo/IMG/pdf/fin_de_ciclo-2.pdf.

Recebido em 27/08/2018

Aprovado em 27/09/2018

Conflito de interesses: inexistente

Suporte financeiro: não houve 